\title{
The literary and recent scientific history of the earworm: a review and theoretical framework
}

Article

Accepted Version

Beaman, C. P. (2018) The literary and recent scientific history of the earworm: a review and theoretical framework. Auditory Perception \& Cognition, 1 (1-2). pp. 42-65. ISSN 2574-2450 doi: https://doi.org/10.1080/25742442.2018.1533735 Available at https://centaur.reading.ac.uk/79201/

It is advisable to refer to the publisher's version if you intend to cite from the work. See Guidance on citing.

To link to this article DOI: http://dx.doi.org/10.1080/25742442.2018.1533735

Publisher: Taylor \& Francis

All outputs in CentAUR are protected by Intellectual Property Rights law, including copyright law. Copyright and IPR is retained by the creators or other copyright holders. Terms and conditions for use of this material are defined in the End User Agreement.

www.reading.ac.uk/centaur

\section{CentAUR}


Central Archive at the University of Reading

Reading's research outputs online 
The Literary and Recent Scientific History of the Earworm: A Review and Theoretical Framework

\author{
C. Philip Beaman \\ School of Psychology \& Clinical Language Sciences, \\ University of Reading
}

Address correspondence to:

School of Psychology \& Clinical Language Sciences,

University of Reading, Earley Gate, Whiteknights, Reading RG6 6AL, UK.

Tel: +44 (0) 1183787637

Email: c.p.beaman@reading.ac.uk

Running Head: HISTORY OF THE EARWORM 


\begin{abstract}
The phenomenon of the earworm - the song that replays within the head and will not go away - is reviewed. Earworms have been of interest to commentators for some time, as demonstrated by their appearance in popular culture. Despite this popular interest, and the speculative links sometimes drawn between earworms and clinical conditions such as Obsessive Compulsive Disorder (OCD), they have attracted empirical investigation from music psychologists and auditory cognition researchers only recently. A number of implicit assumptions about the phenomenon are evident within the empirical literature but no theoretical rationale for the earworm has been put forward explicitly. Historical and literary accounts of music being "stuck in the head" are reviewed for their accuracy relative to more recent empirical findings about earworms. A short account, based upon existing knowledge and theorizing in cognitive psychology, is then sketched out as a guiding framework for future empirical work. Some predictions of this "business-as-usual" theory of earworms are shown to be supported by more recent data.
\end{abstract}

Keywords: Earworms, involuntary musical images, auditory imagery, ironic mental control 
Most of us at some time have had the experience of a piece of music running, apparently uncontrollably and without conscious volition, through our heads. These experiences have been described in a number of ways: as "sticky music" or "brainworms" (Sacks, 2007), "musical imagery repetition" (Bennett, 2002), "stuck song syndrome" (Levitin, 2006) "intrusive musical imagery (IMI)" (Taylor et al., 2014) or a "cognitive itch", (Kellaris, 2001). The most common generic name is probably "earworm", defined by Williams (2016) as "a piece of music that repeats a number of times in the head, without being recalled voluntarily". Although the phenomenon has recently received scientific attention, it is still poorly understood and, in what follows, a historical overview of the phenomenon is given, leading to a "business-as-usual" theoretical framework in which to place the experience. Briefly, it is argued that nothing that has been observed so far warrants any special status for the earworm experience outside of existing theories of relevant mental constructs such as auditory imagery, cued recall, and ironic mental control. Instead, I argue that what makes earworms distinct from other aspects of auditory cognition (and of great interest to the general population as indicated by coverage in the popular press) is the reaction of people experiencing an earworm.

Earworms can take the form of either a complete musical piece or, more frequently, part of the whole. Estimates of the length of such a piece (in terms of time taken for the piece to play) average around 15-30 seconds (Beaman \& Williams, 2010) suggesting that the most common form of an earworm is a single but complete musical phrase or possibly a chorus. Some researchers have attempted to give the earworm a meaningful scientific name, referring to it (or them) as Involuntary Musical Images or INMI (e.g., Beaman \& Williams, 2013; Farrugia, Jakobowski, Cusack \& Stewart, 2015; Floridou, \& Müllensiefen, 2015; Floridou, Williamson, Stewart, \& Müllensiefen, 2015; Liikkanen, 2012; Williamson \& Jilka, 2014; Williamson et al., 2012). The term "earworm" is retained here partly because the more colloquial name is increasingly familiar to the general public but also because using terms such as involuntary musical imagery synonymously with earworms implies that all forms of involuntary 
musical image are equivalent - a (possibly unintended) theoretical commitment that has not been established. It is not clear, for example, what relationship (if any) there may be between earworms and musical hallucinations (e.g., Husain, Levin, Scott \& Fjeldstadt, 2014) or certain forms of tinnitus which may be experienced as music, each of which is certainly both involuntary and musical although they have different aetiologies (see Hubbard, 2010, for a discussion of voluntary and involuntary auditory imagery).

A possible relationship between earworms and musical hallucinations is hinted at in an individual differences study by Beaman and Williams (2013) which showed a small but significant positive association $\left(R^{2}=.21\right)$ between the intensity of the earworm experience (as measured by the sum of a series of questions from Beaman and Williams' (2010) earworm questionnaire) and scores on the Raine schizotypy questionnaire (Raine, 1991), which measures propensity towards schizophrenic and hallucinatory episodes in a normal population. Schizotypy measures index the reported vividness and frequency of images which are experienced as appearing involuntarily so it is reasonable to hypothesise a link between earworms and schizotypy, although there is nothing intrinsically musical about the experiences measured on schizotypy scores, and the causal direction of the association is not known. Such a link might reflect either an increased tendency towards earworms amongst those scoring high in schizotypy or, more prosaically, an increased willingness to label musical imagery of all kinds as “involuntary". Beaman and Williams' (2010) finding was replicated by Cotter, Christensen and Silvia (2016) using different measures of both schizotypy and earworm intensity but this possibility awaits further confirmation and follow-up research. Nevertheless, a tentative first step in identifying the place of earworms in auditory cognition is to suggest that they are a form of involuntary cognition that need not differ qualitatively from other involuntary phenomena which are part of everyday (i.e., subclinical) experience. 
In what follows I review phenomenological data on earworms, followed by a consideration of earworms in terms of specific cognitive constructs: the "sticky tune", the auditory image, and the unwanted thought. A simultaneous consideration of earworms from all of these perspectives allows for the first explicit attempt to provide a theoretical framework within which the earworm phenomenon can be positioned.

\section{Phenomenology of the Earworm}

The nature of earworms is such that they are primarily phenomenological, that is they are things which are experienced. As such, it is logical to start with the features which, by common (or at least, majority) consent characterize the earworm experience. The first source of introspective data regarding earworms comes from fiction by famous and best-selling authors of a period pre-dating both standardised questionnaire studies and readily available recorded music. Despite their avowedly fictional nature, such stories are reliant upon their readership recognising and identifying with the experiences described, so these stories represent out best sources for data about earworms for Western musical forms from an era pre-dating recorded music of all types. Suggestions about the nature of earworms from these sources are considered in the light of more recent, and more objective, studies. The second source of similarly subjective and experiential data has been obtained more recently in large-scale questionnaire based research. Following this review of how earworms are experienced by those who are aware of involuntarily generating musical imagery, more objective data on earworms are considered.

The Earworm as a Subject in Fiction 
The appearance of earworms in literature and popular culture - although not necessarily referred to by that name - predates the modern scientific interest by some considerable time. Possibly their earliest appearance in English was in Edgar Allen Poe's (1845) short story “The Imp of the Perverse ${ }^{11}$ In that story Poe describes the unwanted appearance of music in the head in the following terms:

"I could scarcely get rid of it for an instant. It is quite a common thing to be thus annoyed with the ringing in our ears, or rather in our memories, of the burthen of some ordinary song, or some unimpressive snatches from an opera. Nor will we be the less tormented if the song in itself be good, or the opera air meritorious. ${ }^{\prime 2}$ (p.283)

Three observations immediately follow from this quotation. The first is that Poe explicitly complains about the unwanted, intrusive nature of the earworm and this is also a common modern reaction. A google search for the term "earworm" (7/12/17) revealed that half of the top 10 matches were devoted to discussions of how to get rid of unwanted earworms. This is consistent with Liikkanen's (2008) finding that music was not only the most commonly reported involuntary image, it was also the most likely to be judged as disturbing. Additionally, automatic data classification and sentiment analysis reveals that earworms are most commonly appraised negatively on social media platforms such as twitter (Liikkanen, Jakubowski \& Toivanen, 2015). However, although earworms apparently appear involuntarily, a negative reaction is not a necessary condition of Williams' (2016) definition of an earworm. Questionnaire studies reliably reveal that, for the majority of people, the experience of an

\footnotetext{
${ }^{1}$ Thanks to Lassi Liikkanen for drawing this to my attention.

${ }^{2}$ The "I" in this quotation refers to Poe's unnamed protagonist.
} 
earworm is not unpleasant and may in some cases be actively enjoyable (e.g., Halpern \& Bartlett, 2011). Nonetheless, a negative reaction to the appearance of an earworm is an immediately recognisable experience.

Secondly, Poe is very clear that the "ringing" about which he complains arises not so much in the ears as in the memory (thereby potentially dissociating it from musical tinnitus) and therefore represents an involuntary musical recollection. This suggests that earworms are primarily a memory phenomenon and accords with more recent findings that earworms are both more likely to involve wellknown songs or melodies, for which there is a strong long-term memory representation (Beaman \& Williams, 2010; Williamson \& Jilka, 2014; Williamson et al., 2012), and to more frequently involve recently encountered tunes for which, again, one would expect memory to be more active (Byron \& Fowles, 2015; Kvavilashvili \& Mandler, 2004; Halpern \& Bartlett, 2011; Hyman et al., 2015; Williamson et al., 2012). This mnemonic aspect of the experience will be considered in more detail later in this paper.

Finally, Poe notes that the musical highpoints or shortcomings of the piece are irrelevant to its appearance as an earworm. The musical characteristics required for an earworm to be formed is a question that more modern research has only just begun to address (Jakubowski, Finkel, Stewart \& Müllensiefen, 2017) along with the individual and personal characteristics of people who are more likely to experience such earworms (Beaman \& Williams, 2010, 2013; Farrugia, Jakubowski, Cusack \& Stewart, 2015; Hyman et al., 2015; Liikkanen, 2012; Müllensiefen, Fry, Jones, Jilka, Stewart \& Williamson, 2012; Williamson \& Jilka, 2014; Williamson et al, 2012).

The earworm re-appears in literature (again, not by name) in Mark Twain's 1876 short story “A Literary Nightmare" (originally titled, "Punch, brothers, punch") which restates Poe's point about the negative reactions to an earworm, going so far as to claim that because of the earworm - the "relentless jingle" as it is described - "(t)he day's work was ruined" (p. 5). This extreme reaction was not evident 
amongst respondents to Beaman and Williams' (2010) questionnaire, however, most of whom claimed that their earworms were not disruptive in this way (a pattern of data also largely replicated in Beaman \& Williams, 2013). An interesting facet of Twain's story is that the "relentless jingle" is not, originally, a tune or melody at all but rather a rhyme (a series of couplets beginning, "Punch, brothers punch") which was encountered in written form and therefore the "jingle" arises from the meter of the rhyme presumably as it was read aloud. There is no indication in most modern studies of the origin of earworms that many earworms are generated from encountering song lyrics in written form (Williamson et al., 2012).

Twain's story includes a number of other interesting elements that have received mixed support from modern research. In his story, “....my feet were keeping time to that relentless jingle. When I could stand it no longer I altered my step. But it did no good; those rhymes accommodated themselves to the new step and went on harassing me just as before" (p. 5). The potential for such entrainment of motor behavior by the earworm was observed by Jakubowski and colleagues who showed that participants in their study were able to reproduce the tempo of an earworm with high degree of accuracy when asked to do so (Jakubowski, Farrugia, Halpern, Sankarpandi \& Stewart, 2015). Similarly, although perhaps less extreme than Twain's idea of the jingle overpowering the poor narrator, Williamson and Jilka (2013) noted that interviewees with musical experience also reported visual and motor imagery accompanying the earworm (cf., Bailes, 2007). It is not reported whether these individuals experience any similar synaesthetic experience involving non-musical imagery although it is not uncommon for synaesthesia to accompany musical stimuli amongst synaesthetes (e.g., Ward, Huckstep \& Tsanikos, 2006). The opposite pattern of results has also been reported, that is that motoric involvement with a tune (e.g., dancing, tapping or singing along) promotes the subsequent appearance of an earworm (McCullough Campbell \& Margulis, 2015). 
Elsewhere, support for some of Twain's statements is less forthcoming. Twain's story includes the comment that,

"I returned home, and suffered all the afternoon; suffered all through an unconscious and unrefreshing dinner; suffered, and cried, and jingled all through the evening; went to bed and rolled, tossed, and jingled right along, the same as ever...." (p. 5)

This claim by the (fictional) narrator that the earworm lasted all day, all night and well into the next day was not borne out by a diary study reported by Beaman and Williams (2010) which showed that the same earworm recurred infrequently and very rarely lasted more than a single day. A phenomenon known as the "perpetual music track" (Brown, 2006) has been reported, in which individuals affected report the constant presence of music "in their heads" but, similarly to musical hallucinations, it is not entirely clear whether these involuntary musical experiences should be classified as earworms and they also differ somewhat from Twain's characterization in that the music experienced changes over time - it is not always the same tune - and they appear to be lifelong. As one email correspondent has put it,

"I have musical ear worms $24 / 7$ ever since I can remember. I found out 7 years ago this was not 'normal'; I thought everyone always had music playing in their heads but apparently this is not the case" 
In Twain's story, by contrast, the narrator "contracted" the earworm by reading the rhyme and eventually gets rid of it by passing it on to someone else. There is, of course, no cognitive or physiological reason why infecting someone else with it should rid oneself of an earworm but there may be a scientific basis for at least some degree of earworm contagion (e.g., Liikkanen et al., 2015).

In summary, early literary accounts of the earworm not only confirm its existence in a society predating the ready availability of recorded music, presenting it as something both familiar to their readership and worthy of literary effort, but they also prefigure many features of the earworm recognizable to modern-day audiences: These accounts highlight the intrusive and sometimes unpleasant nature of the experience, explicitly link the experience to musical memory, and note that the features of a tune which give rise to an earworm are not easily predicted $a$ priori although rhythm and tempo are important to the experience within these accounts.

The Earworm as a Subject of Self-report

American short story writers of the nineteenth century presented fictional accounts in English of earworm-like experiences but the term "earworm" is a direct borrow from German, being a literal translation of the German word ohrwurm. The German language literature is also where the first scientific studies of earworms can be found. Papers by Eckert (1989), De La Motte (1993) and Hemming (2009) largely predate the first discussions of earworms in the English scholarly literature. The earworm makes an (unnamed) appearance in English in a brief article on "obsessive tunes in normal persons under stress" (Berg, 1953) and then, much more recently in an unpublished MPhil dissertation by Bennett (2002). This study was followed by a number of large-scale internet questionnaire studies which provided descriptive data on the nature and prevalence of the earworm in the general population (e.g., Liikkanen, 2008). 
By definition, music "in the head" is a subjective experience lacking an objective, external reality against which it can be compared in standard psychophysical style and initial scientific studies of earworms were largely descriptive, and reliant upon self-observation studies. The majority of these have been questionnaires of some form (Beaman \& Williams, 2010; Halpern \& Bartlett, 2011; Liikkanen, 2008; Williamson et al., 2012), although diary and experience-sampling studies were also included (Beaman \& Williams, 2010; Floridou \& Müllensiefen, 2015; Halpern \& Bartlett, 2011) as well as intensive interviews (Williamson \& Silka, 2013). As such, the data from these studies is open to standard criticisms of these methodologies, principally that the results might be distorted either by intentional deception or false reporting or else by unintentionally skewed recollection or other memory failings (but see Reason, 1993). Despite these potential worries, and although different sampling methods used and questions posed in the questionnaires makes direct comparison of findings across studies impossible, the findings across independently conducted studies are, nonetheless, remarkably reliable overall.

The first point to note is that the prevalence of earworms amongst the populations so far surveyed is very high in all studies, with $91.7 \%$ of 12,420 Finnish internet users reporting earworms at least once per week (Liikkanen, 2008), 88\% of 229 participants completing an online survey for Western Washington University reported earworms either sometime the same day or "sometime in the last few days" (Hyman et al., 2012) and 13/18 (72\%) of undergraduate students in a diary study at the University of Texas at Dallas reporting the experience either a few times a week or almost daily (Halpern \& Bartlett, 2011). The next questions most commonly posed are whether there are particular personality or demographic characteristics which predispose to earworms, whether some songs are more likely to become earworms than others and whether there are common "triggers" for earworms.

In response to the first of these questions, a frequently reported finding is that musicality in some form predisposes to experiencing earworms. In Liikkanen's (2008) study, both active musical 
interest and musical training increased the frequency of earworms and this general finding was replicated by Beaman and Williams (2010) who also found that participants who considered music important to them were more prone to earworms. What is not clear from these studies is whether such participants are more prone to earworms because of some underlying cognitive difference between the musically inclined and their less musical counterparts or whether those with musical interests are simply more likely to seek out music in their environment and hence earworms are more likely to be cued. These possibilities are not, of course, mutually exclusive and an interest in music could plausibly result in both more frequent exposure to music and a resultant neurocognitive adaptation meaning that the response to music also differs. At least one study (Farrugia, Jakubowski, Cusack \& Stewart, 2015) reported an association between individual differences in earworm frequency and cortical thickness in brain regions associated with auditory perception and imagery (e.g., Heschl's gyrus, anterior pre-supplementary motor area; Farrugia et al., 2015). Other personality or demographic variables which have a priori been considered candidates for more frequent earworm experiences include the predispositions to hallucinatory experiences already discussed and to obsessive compulsive disorders (Levitin, 2007; Müllensiefen et al., 2014) and the desire to suppress unwanted thoughts (Beaman \& Williams, 2013).

Attempts to identify particular musical characteristics of songs that become earworms have also been bedeviled by the idiosyncratic nature of the earworm experience - the tendency for recent and well-known songs or melodies to become earworms which makes every earworm experience personal (if not necessarily unique). The most comprehensive study of the musical features which go to make up an earworm to date is by Jakubowski and colleagues (2017), who directly compared the melodic features of tunes reported as earworms by at least three questionnaire respondents (out of a total of 3000) with songs that were never reported as earworms but were recorded by the same or "similar" artists and/or from similar time periods, chart positions and musical genres (Jakubowski, Finkel, Stewart 
\& Müllensiefen, 2017). Clearly any such matching of a "non-earworm" control group will necessarily be inexact, and the results (which show a relative difference between earworm and control songs) will reflect this, but nonetheless the attempt showed that tunes identified as earworms tended to have a faster tempo than their matched controls and were also less unusual in terms of their melodic contour, that is, the pattern of rising and falling of pitches within the tune was more in line with established Western musical norms - Owner of a Lonely Heart by Yes and Smoke on the Water by Deep Purple are examples of earworms which have a more common global melodic contour whereas Rock $N$ Me by the Steve Miller Band and Plug in Baby by Muse are examples of non-earworm controls which have less common melodic contours. As noted by the authors, this study specifically examined melody so it is also unknown whether other abstract features of the songs used (such as lyrical content) or specifically auditory perceptual features (e.g., timbre, loudness) also contribute to tunes becoming earworms in addition to structural features such as temp and melodic contour.

One reason why specific acoustic or musical characteristics of earworms might be difficult to identify is that, as also reported by Jakubowski et al. (2017), situational factors such as the recency with which a song has been heard also dictate the likelihood of it appearing as an earworm. From the perspective of earworms as musical recollections, this makes sense: it is well known that recently encountered items - in particular recently encountered auditory items - are readily recalled (e.g., Baddeley \& Hitch, 1993; Conrad \& Hull, 1968). One argument, put forward by Baddeley and Hitch (1993) is that the ubiquitous observation of recency effects in free recall of diverse types of material reflects an intentional recall strategy (as required in the usual experimental situation) superimposed upon incidental learning (in naturalistic studies, which also show recency, the material was not necessarily deliberately encoded for later recall). It is a simple extension from this to suggest that similar recency effects might occur in the absence of intentional recall and such effects would give rise to the observed pattern of involuntary musical recollections being more frequent for tunes that have been more recently 
encountered, although the exact interplay of variables which give rise to these results is complex even under closely-controlled experimental conditions.

The cue-driven nature of memory retrieval also dictates that any feature which will make a stimulus (such as a tune) memorable under certain conditions may be less effective under other conditions (the encoding-retrieval principle; Surprenant \& Neath, 2009). An obvious example of this is the von Restorff isolation effect: a jazz instrumental encountered amongst a collection of country and western ballads will be more readily recalled than any single one of the ballads and more readily recalled also than when the same jazz tune is surrounded by other jazz instrumentals (von Restorff, 1933). Thus, anything which brings a song to mind under some conditions may be less likely to bring the same song to mind when those conditions change. Similarly, auditory (and other) recency effects can be reduced by subsequent auditory stimulation (e.g., Campbell, Beaman \& Berry, 2002; Crowder \& Morton, 1969). There may be circumstances, however, under which a song is more likely come to mind unbidden even if the identity of the song may vary between individuals and within the same individual over time. These include not only recent and repeated exposures (Jakubowski et al., 2017; Williamson et al., 2012) but also particular mnemonic associations or memory cues, affective and attentional states (Williamson et al., 2012) and situations of particularly high - or particularly low - cognitive load (Hyman et al., 2013). In Hyman et al.'s (2013) study, there was no straightforward relationship between earworm reports and cognitive load - rather there seemed to be a non-monotonic relationship such that more earworms were reported when cognitive was either very low (resulting in little cognitive demand) or very high (potentially overloading cognitive resources). Such circumstances give rise to unfocussed thought processes which might encourage mind-wandering and the random cueing of musical memory and specific memory cues or types of memory cue (e.g., affective state), all of which suggest that earworms might be cued in much the same way as other involuntary memory experiences (Kvavilashvili \& Mandler, 2004; Kvavilashvili \& Schlagman, 2011). Note that "cognitive load" is used here in a generic 
sense with no intended reference to cognitive load theory (Lavie, 1995) which, despite its successes in accounting for data on visual selection has received rather more mixed support when applied to the auditory domain (Murphy, Spence \& Dalton, 2017).

In summary, self-report data in the form of questionnaires and diary studies reviewed here again emphasizes the ubiquitous nature of the earworm phenomenon. This is to be expected if the experience is a by-product of normal functioning of cue-driven memory although it begs the question of why other involuntary recollections have not the same apparently widespread recognition. Musical features of a tune which might result in an earworm have proven elusive - again, as one might expect from basic mnemonic principles which emphasize the interplay between the cue and the environment rather than features of the stimulus - however individual differences studies suggest that musicality in some form is important although, as with the relationship with schizotypy, the direction of causality is difficult to ascertain from these data alone.

\section{Earworms as "sticky tunes"}

Notwithstanding the research showing that earworms need not be unpleasant and may be actively enjoyed (e.g., Halpern \& Bartlett, 2011) there is good reason to believe that earworms can sometimes be unwanted and actively resisted (e.g., Liikkanen et al., 2015). As noted initially, a striking feature of earworms, arguably their most striking feature, is the way in which people react to them. Assuming that people do try and remove unwanted earworms, what strategies are likely to be effective and what makes earworms "sticky" in the first place? As argued above, it is theoretically parsimonious to suppose that earworms are a form of musical recollection and are triggered in much the same way as other involuntary recollections. Where earworms differ from most involuntary recollections (excluding pathological cases such as the visual flashbacks which can accompany post-traumatic stress and similar 
disorders) are the sensory experiences and emotional reactions they trigger, and the way they seemingly repeat as if stuck in a playback loop. These features, however, can also be explained within contemporary cognitive theories of memory and auditory imagery.

To qualify as an earworm, a song must in some sense be "heard" within the head - there needs to be an auditory image of the song. Regardless of the form of the underlying representation, a priori an earworm has to unfold over time in order to be experienced as such. This necessary feature is important because - like most auditory stimuli - music is inherently temporal: While one could imagine a static visual image, and such an image would be meaningful, it is not possible to imagine "hearing" a tune except as it plays over time. Apart from the logical problems inherent in trying to imagine a tune in the absence of such sequential and durational information, it has also been demonstrated empirically that to "hear" a tune in one's head requires a temporal component . For example, the finding that reaction times when asked to compare the pitches of two notes within a song increase as a function of the number of intervening beats (Halpern, 1988) indicates that the notes are not directly accessible and the intervening period between the notes must be traversed over time before the pitch comparison can be made. How far along the melody the tune "plays" then reduces to the question of how large (in some sense) a typical musical memory might be - admittedly a problematic issue but, if this analysis is correct, one which at least tentatively can be answered by pointing to the typical "length" of an earworm (Beaman \& Williams, 2010). This statement might seem to commit earworms to a depictive rather than a descriptive representational format for auditory imagery but this does not necessarily follow. In the same way that the time taken to perform visual transformations originally interpreted as evidence for analog representations (Kosslyn, 1994) can be reinterpreted in terms of propositional representations (Pylyshyn, 2003) time taken to "read-off" from an auditory image is accountable in both depictive and descriptive terms. The key point here is not that the depictive/descriptive debate can be resolved through investigation of earworms (it cannot) but rather that if convincing data emerge that voluntary 
musical recollections are either descriptive or depictive in format and earworms are not, then the business-as-usual approach to earworms is falsified because this will demonstrate that earworms are fundamentally different in type from other musical memories.

Any musical recollection which is also involuntary (a further a priori requirement) necessarily also results in one of three subjective appraisals - the tune is evaluated positively, the person is neutral with respect to their experience of the tune, or they evaluate the tune negatively. If the tune is evaluated neutrally then nothing much follows as the person is motivated neither to encourage nor to reject the experience. The earworm may still persist because of the unfolding nature of a musical memory but will not recur unless the individual starts to ruminate upon the tune, in which case (like any memory) it will be reactivated and - being a musical memory - will replay. If this happens then it is plausible that the emotional reaction to the tune will shift from the initially neutral status - if the recurrence is annoying, this will shift towards a negative evaluation but if the recurrence is enjoyable then the emotional reaction will be positive.

If the tune is evaluated positively then the memory might be consciously reactivated so that an initially involuntary musical memory might become a voluntary musical recollection. Such an experience might presumably retain its Involuntary Musical Imagery status for purposes of scientific investigation by virtue of the fact that the initial occurrence was involuntary but this rather fine distinction has not been made in the literature. If the tune is evaluated negatively then the individual may try and actively suppress the recollection with counter-productive results. As documented by Wegner and colleagues (e.g., Wegner, 1994; Wegner, Schneider, Carter \& Wright, 1987) the attempt to suppress a given thought can often rebound, making the thought more rather than less accessible. For example, participants asked not to think about white bears for three minutes reliably report numerous white-bear related thoughts over this period (Wegner, 1989; see also Storm, Bjork \& Bjork (2008) for examples of 
attempts to forget making memories subsequently more accessible). Thus, attempting to suppress an unwanted earworm could in itself reactivate the earworm. In the next section, evidence for tunes becoming "sticky" by virtue of their unwanted nature is evaluated, along with recent data on attempts to block such sticky tunes.

Earworms as unwanted thoughts

The claims above are based upon a number of assumptions. The first assumption is that attempts to control earworms are governed by the counterproductive processes Wegner (1989) termed "ironic mental control" in which attempting to suppress an earworm will actually make the earworm more accessible. This is consistent with a business-as-usual approach. However, a qualitative analysis of what people claim to do when they experience earworms revealed that attempts to "suppress" earworms were surprisingly few in number and that direct attempts to manage unpleasant earworms are often reported to be effective (Williamson, Liikkanen, Jakubowski \& Stewart, 2014). This was interpreted as refuting the application of ironic mental control theory to earworms (Williamson et al., 2014) but this conclusion is premature for two reasons.

It relies firstly upon an assumption that metacognitive monitoring of the effectiveness of such strategies is accurate. Although self-report data on earworms has largely been consistent across studies, metacognitive monitoring is known to vary in its accuracy, particularly with regard to estimates of one's own ability to control events (Wegner, 2002, reviews instances of both accurate and inaccurate feelings of control) and estimates of temporal duration can be systematically distorted by music (Droit-Volet, Ramos, Bueno \& Bigand, 2013) and other auditory events (e. g., "click trains", Penton-Voak, Edwards, Perceval \& Wearden, 1996) even when participants are asked to actively ignore anything they may hear (Hanczakowski, Beaman \& Jones, 2018), although it is not clear whether this result extends to internally- 
generated auditory imagery. In Williamson et al.'s study, participants were asked to report activities they believed were successful in ridding themselves of earworms and the feeling of control might be heightened by the awareness that the earworm did eventually disappear and by the lack of any comparable "control" condition to estimate earworm duration when trying to "remove" the earworm versus when not making such attempts - in this non-experimental study no such control was available either to the participants (to calibrate their metacognitions) or the researchers (to check this calibration).

Data from Beaman and Williams (2010) are relevant to this issue although these data also need to be viewed with caution. In their diary study, Beaman and Williams (2010) asked participants to record the duration of earworm episodes experienced over the period of the study and then broke this down by displacement activity type - none, "specific interference", or "general distraction". They reported that both specific interference and generalized distraction increased the reported duration of the earworm episode. These estimated durations are still subject to the criticism that participants may have been inaccurate in their self-reports, but these durations were noted down closer to the actual time of the earworm experience and critically the participants were not cued to provide their own judgments of a successful attempt at ridding themselves of the earworm - they simply provided the estimated duration of the earworm before the data were categorized and the durations compared statistically, providing a more objective measure. A second criticism of the Beaman and Williams (2010) study is its small sample size - particularly when compared to the large online questionnaire results reported by Williamson et al. (2014) - although the by-item analysis (with participant as a fixed factor) which was necessary in this study because of the lack of experimental control with such an observational design mitigates this criticism to some degree. 
Further evidence for the involvement of ironic mental control in the earworm experience comes from Beaman and Williams' (2013) individual differences study, which found that thought suppression as measured by Wegner and Zanakos's (1994) White Bear Suppression Inventory (WBSI) was associated with measures of the length and disruptiveness of earworms and the difficulty experienced in dismissing them. A clear qualitative difference here between Beaman and Williams (2013) and the Williamson et al (2014) study is that Williamson et al. specifically asked participants to list activities they found effective in dealing with earworms whereas, as emphasized by Wegner and Zanakos (1994), the WBSI is not intended to measure either failed or successful suppression by any particular means, rather it is intended to be sensitive to "the conscious desire to suppress thoughts" (Wegner \& Zanakos, 2014, p. 638 , emphasis in original). Thus, the association reported in the Beaman and Williams (2013) study is not between any particular form of thought suppression and earworms but between the desire to suppress thoughts and earworms, regardless of how that desire might be acted out.

As already noted in other contexts, Beaman and Williams' (2013) study was also correlational in design so it is not clear, for example, whether a desire to suppress earworms could have an ironic effect on the number of earworms experience or the length of earworm episodes or whether an unusually frequent or lengthy experience of earworms might result in a more fervent desire to rid oneself of them. Anecdotal evidence in favor of the latter possibility comes from the fictionalized accounts given earlier as well as from personal accounts of individuals who find their own experience of seemingly endless music "in the head" distressing (assuming that these accounts can be characterized as earworms) and Beaman and Williams' (2013) other main finding that WBSI scores were strongly associated with schizotypy, which measures frequency and vividness of involuntary thoughts and images.

To obtain more direct evidence about a causal role for ironic mental control in the earworm experience, Beaman, Powell and Rapley (2015) made use of the basic procedure thought suppression 
employed by Wegner and colleagues in their studies (e.g., Wegner et al., 1987). Beaman et al. played their participants a target song and then asked them not to think about it for three minutes. During these three minutes participants were required to press a key whenever the song came to mind. As with Wegner's studies (Wegner, 1989, 1994; Wegner et al., 1987), participants who were asked not to think of a particular song found this task very difficult, as revealed by an average of about 9 key presses (approximately one every 20s assuming they were evenly spaced) over the three minute period (Beaman et al., 2015, Experiment 1).

In a crucial change from Wegner's methodology, Beaman et al. went on to ask participants to press one key if they merely "thought" of the tune and another if they "heard" it in their head. This ensured that the precondition of an earworm experience that the music should "play" in the head was met $^{3}$. Under these conditions, approximately $3 / 4$ of the earworm-related thoughts were revealed as the music "playing in the head" (Beaman et al., 2015, Experiment 2). This manipulation was necessary not only to meet the criticism that without evidence that the song was "playing" in the head there is no evidence of an earworm per se, but also because the theoretical account of earworms gives prominence to the auditory imagery aspect of the experience over the unwanted thought aspect. Ironic mental control requires that there be a goal to rid oneself of an unwanted thought but, as has now been amply documented, involuntary musical images (in their widest sense) are not necessarily unwanted simply because they are involuntary. Thus, although it is true that an individual might have a goal to rid themselves of an involuntary musical image - and according to this theoretical account such a goal may have consequences - wishing to do so is not a necessary feature of an earworm.

It is also important to note that although the word "suppression" is used frequently in Wegner's theorizing (e.g., Wegner, 1994) it is used neutrally and is not necessarily intended to imply active

\footnotetext{
${ }^{3}$ This requirement that participants should report the conscious experience of sound in any study of auditory imagery is not always fulfilled, even in high-profile studies (e.g., . Kraemer, Macrae, Green \& Kelley, 2005).
} 
attempts at repression or inhibition or any similar psychodynamic or neurally-inspired concept. The possibility of self-distraction is given at least equal weight in these studies - for example by asking participants to thinking of a red Volkswagon as a means of avoiding thinking of a white bear (Wegner et al., 1987) which parallels participants' self-reports of attempting to think of another song or simply "something else" (e.g., Beaman \& Williams, 2010; Williamson et al., 2014) to displace an unwanted earworm.

The distinction between the goal to rid oneself of an unwanted earworm and the types of activity used to attempt to meet this goal is an important one because the goal and the earworm, it is presumed here, exist independently such that the goal might persist as a representation in a goal-buffer or similar cognitive construct (e.g., Anderson, 2007; Beaman, 2010; Newell, 1990) independently from the representation of the music itself, which will be maintained elsewhere in the cognitive architecture in whatever storage systems or processes are responsible for auditory imagery and auditory memory. A "goal buffer" is simply a means of maintaining and prioritizing various task-relevant goals as required within a larger cognitive architecture for computer simulations of human cognitive performance (Anderson, 2007; Newell, 1990; Shallice \& Cooper, 2011) Thus the subjective earworm experience is dictated by both the goal (either to maintain or to dismiss an involuntary musical recollection) and the representation of the music itself. Goals to dismiss an involuntary musical recollection can be counterproductive, as shown by Beaman et al. (2015), if checking whether the goal has been met (the earworm has gone) cues the earworm to "replay". However the earworm experience is at least as dependent upon the operation of auditory memory and auditory imagery once the musical recollection is cued.

A number of conclusions follow from the application of the theory of ironic mental control outlined above and can be summarized as follows. If the assumption is correct that the representation of the tune itself is unremarkable, despite being involuntary and possibly unwanted, then aspects of 
auditory imagery revealed by other auditory imagery studies (as, for example, reviewed by Hubbard, 2010) should surely apply to earworms. One consequence of this is that the fine distinction drawn earlier between an initially involuntary musical recollection that is evaluated positively and becomes consciously supported and a musical recollection that remains involuntary because it is unwanted then becomes trivial so far as the representation of the music itself is concerned. A second consequence is that participants' scores on established measures of auditory imagery should be correlated with their earworm experiences and activities documented as interfering with auditory imagery should reduce participants' reports of earworms.

\section{Earworms as auditory images}

The assumption made in the outline account of earworm generation and maintenance is that the earworm per se is qualitatively similar to, and may be indistinguishable from, other auditory cognitions in terms of their basis in auditory imagery and memory. This assumption is implicit in some of the distractions participants seek out in Williamson et al.'s (2014) report, which often follow a pattern of participants assuming that like will displace or interfere with like, consistent with assumptions ofren made within the memory literature (e.g., Nairne, 1990; Surprenant \& Neath, 2009). This suggestion was also made more explicitly with respect to earworms in Hyman et al. (2013), which looked at the effects both of general cognitive load and specific (verbal) dual-tasks which were assumed to interfere with auditory imagery by disrupting inner speech (Smith, Wilson \& Reisberg, 1995). This dual-task interference approach was also taken by Beaman et al. (2015) who found that a vigorous chewing action reduced the number of earworms reported, directly paralleling the findings from voluntary auditory imagery (Smith et al., 1995) and verbal short-term memory (Kozlov, Hughes \& Jones, 2012). 
In a more direct attempt to examine the involvement of auditory imagery in involuntary and (in this case) unwanted musical imagery, Beaman et al.'s (2015) procedure was repeated with a sample of 40 undergraduate participants and using a different target song (Shape of You, by Ed Sheeran ${ }^{4}$ ). Full method and results are given in the appendix. Beaman et al's (2015) finding that participants reported both unwanted thoughts of the target song and - more frequently - unwanted earworm experiences of the song was replicated but, in this case, the participants also completed the Bucknell Auditory Imagery Scale (BAIS; Halpern, 2015), a validated auditory imagery scale comprising of separate subscales for vividness and control of auditory imagery. Table 1 gives the Pearson's correlation coefficients between these measures and the number of times the participants reported "thinking about" or "hearing" the target song. As this table shows, the correlations between involuntary thoughts and the imagery scales were minimal whereas the correlations between involuntarily "hearing" the song and the BAIS subscales were both substantial -comparable to the correlation between the two BAIS subscales - and statistically significant.

\section{TABLE ONE ABOUT HERE}

These results show that "hearing" the song, but not merely thinking about it, is associated with independent measures of auditory imagery - this association is predicted on the basis that earworms are products of the auditory memory and imagery systems which the BAIS reflects. Figure 1 shows scatterplot graphs of these two correlations together with lines of best-fit, and provides reassurance that the significant correlation coefficients were not driven by a small number of outliers. The exact

\footnotetext{
${ }^{4}$ in all these studies target songs were selected as potential earworms by student researchers in order to roughly match the age, sex and socio-economic demographics of the research participants
} 
form of the association is somewhat surprising because a negative correlation is equally plausible $a$ priori. Participants scoring highly on the BAIS - and the control subscale in particular - could easily have been those who found it easier to suppress unwanted musical images. Although an auditory rather than a specifically musical imagery scale was used, these data are nevertheless consistent with the reports that an interest in, or proficiency with, music leads to more self-reported earworms and also with Farrugia et al's (2015) finding that scores on the Goldsmiths Musical Sophistication Index (Mullenstein, Girgras, Musil \& Stewart, 2014) predict earworm frequency. The data further suggest that the basis for this might be cognitive (vividness and control of auditory imagery) rather than environmental (more music in the environment cuing the earworms). Although a mediating factor of music within the environment cannot be ruled out: more frequent reports of earworms amongst the musically inclined (e.g., Beaman \& Williams, 2010; Liikkanen, 2008) could have been a byproduct of musicians and those interested in music seeking out and being more aware of music, resulting in both more overlearned tunes and more frequently (hence, more recently) encountering music within their environment these results show that participants with a rich auditory inner life, as indexed by their self-reported results in an auditory imagery scale, are also more likely to cue musical recollections involuntarily when exposed to Beaman et al's (2015) experimental manipulation. This state of affairs would also result in more reported earworms in questionnaire studies amongst such individuals. An interesting question not addressable by any current data is whether, using Beaman et al's (2015) procedure reported incidences of earworms are clustered together or whether they are more evenly spaced out over the time tested ${ }^{5}$. The view that involuntary recollections as cued suggests that a clustered distribution is perhaps more likely, but this is an empirical question.

\footnotetext{
${ }^{5}$ Thanks to an anonymous reviewer for raising this point
} 


\section{FIGURE ONE ABOUT HERE}

Further results using this technique also reinforce the idea that earworms are supported by auditory memory and imagery systems in a similar manner to voluntary auditory imagery. Substantial data exist on interference effects in voluntary auditory imagery showing that, for example, counting aloud reduces the rated vividness of an auditory- verbal sequences whereas spatial tapping has a much smaller effect (and vice versa for the rated vividness of a visual-verbal sequence; Baddeley \& Andrade, 2000). Both verbal memory and auditory imagery are disrupted by the concurrent articulation of an irrelevant sequence (e.g., mouthing the sequence of letters $A-G$ ) or a vigorous chewing action (Kozlov et al., 2012; Murray, 1966; Reisberg, Smith, Baxter \& Sonenshine, 1989; Smith et al., 1995). By analogy, Beaman and colleagues hypothesized that chewing gum would interfere with the component of auditory imagery and working memory sometimes termed the "inner voice" (Baddeley \& Logies, 1992; Reisberg et al., 1989; Smith et al., 1995), resulting in a disruption to involuntary musical imagery similar to that observed with voluntary auditory imagery (Beaman et al., 2015; Smith et al., 1995). Smith and colleagues provided a priori reasons to suppose that voluntary auditory imagery relies at least in part upon articulatory-motor processing and Beaman et al. (2015) expanded this to involuntary auditory imagery.

In Beaman et al.'s (2015) study, participants were asked in one condition to chew "vigorously" on gum provided while - as in the control condition - trying not to think of the target tune to which they had just listened (either Play Hard by David Guetta featuring Flo Rida and Akon or Payphone by Maroon 5). Participants in these conditions reported fewer earworms than in either a do-nothing (Experiment 2) or tapping (Experiment 3) control. Figure 2 shows similar data from another unpublished study ( $\mathrm{N}=88$, with a $2 \times 2$ between-participants design, see Appendix) in which the target song was either the sung 
version of Shape of You or an instrumental version without the lyrics. The key result is the replication of the disruption caused by chewing gum to the experience of involuntarily "hearing" the target tune. A secondary (and novel) result is that more earworms were reported with the lyrical than with the instrumental version of the tune, which is consistent with the idea that the appearance of tunes with lyrics in lists of popularly experienced earworms reflects more than simply the greater frequency with which the former are encountered. If the interpretation of these results is correct that subvocalization or an "inner voice" is an element of maintaining auditory images that arise involuntarily as well as those which are deliberately rehearsed, then this implies that - in addition to the cortical areas implicated by individual differences investigations (Farrugia et al., 2015) - a functional analysis of earworms could also usefully focus on brain regions such as the supplementary motor area (SMA) which have been implicated in subvocal rehearsal (Henson, 2001; see also Lima et al., 2015; Lima, Krishnan \& Scott, 2016).

Note, however, that there are data which appear to contradict the current suggestion that the articulatory-motor processes underlying short-term memory also supports auditory imagery of all kinds. In their study, Bishop, Bailes and Dean (2013) failed to find a connection between working memory and auditory imagery for loudness. However these data are not as directly applicable to the current situation as might initially appear. Firstly, the form of imagery investigated by these authors was loudness, which is the element least likely to require much articulatory-motor planning. Secondly the working memory measure used was Operation Span (OSPAN) which is generally recognized as loading on much more general (executive) processing than on articulatory motor planning (see review by Aben, Stapert \& Blokland, 2012). Thirdly, the Bishop et al. (2013) examined the role of expertise in imagery, with OSPAN primarily included as a covariate. OSPAN in fact only correlates significantly with one other measure in this paper - this measure being recall and the correlation being negative, which is inconsistent both with theoretical expectations amongst memory researchers and previous empirical results so it seems as though the OSPAN results for this sample are, for whatever reason, unusual. 


\section{FIGURE TWO ABOUT HERE}

\section{Conclusions: A "business as usual" framework for earworms}

The historical review of the concept of an involuntary and possibly unwanted (at least in the fictional accounts) experience of music in the head demonstrates that it is by no means a new phenomenon, although one might speculate that it may perhaps have become prevalent since the advent of recorded music and its widespread availability around the middle of the twentieth century

(e.g., Sacks, 2007). Such recorded music provides for the first time a "canonical" version of any particular song which can be re-experienced note-for-note under a variety of listening conditions and over an such that there will inevitably be multiple potential cues. The involuntary nature of earworms, and the tendency for unwanted earworms to repeat apparently involuntarily, gives a subjective experience of the earworm as something special or out of the ordinary despite the ubiquitous nature of the phenomenon. Certainly the earworm experience requires explanation, however there is nothing particularly special about the tunes that constitute earworms (Jakubowski et al., 2015) and a number of cognitive phenomena which similarly appeared initially to be out of the ordinary are now routinely interpreted in terms of the standard functioning of cognitive processing. So-called "flash-bulb memories", for example, now appear to be no more accurate than normal memories and the subjective feeling of certainty about the memory seem a consequence of subsequent rehearsal of the memory rather than specialized encoding (Talarico \& Rubin, 2003) and, similarly, a case has been made that 
"insight" problem-solving is no different from other forms of problem-solving beyond the subjective feeling of an "aha!) or "Eureka" experience (Weisberg, 2015, but see also Gilhooly, Ball \& Macchi, 2015).

A speculative theoretical framework for viewing earworms as "business as usual", based upon the evidence reviewed above, is outlined in Figure Three. Some or all of the assumptions made in putting together this account may prove to be mistaken, as in any endeavour of this kind, but the theoretical parsimony of the account is attractive and, despite various areas in which the theoretical framework remains somewhat inchoate, it serves as the basis for further empirical predictions. In essence, the framework simply makes explicit some of the assumptions and inferences already drawn here and elsewhere. Earworms are presented as cued musical recollections, where the cue may be either internal (from mindwandering and similar cognitive processes) or external (from the environment) - although it is likely that, in practice, any such cue will be a compound of both internal and external processes. The representational format of these involuntary musical recollections (e.g., descriptive vs depictive) is unimportant to the framework however it is axiomatic that the format does not differ from that of voluntary musical recollections.

The framework as depicted in Figure 3 is also canonical, in that it shows a "standard" information-flow process however there is room within the framework to examine individual differences in any of the components here made explicit. For example, as with any domain of expertise, expert musicians will find it simpler to voluntarily cue a musical memory so (on the basis that involuntary musical recollection is no different in kind from voluntary musical recollection) it can be assumed that this same will also be true of involuntary cues, and experts will also be more frequently in situations where musical memories are cued by the environment. An advantage of outlining the framework in terms of an information-processing "box-and-arrow" diagram is that it makes some of the necessary subcomponents of the cognitive processes involved explicit. In Figure 3, for example, it is possible to 
distinguish between voluntary and involuntary processes, and also between the initial cueing and the subsequent maintenance of an earworm (where he former is always involuntary but the latter need not be). The Figure also delineates the processes which result in the phenomenon known as ironic mental control. It should be noted, however, that cognitive processes identified here can, in principle, be subdivided further. The boxes depicted in the Figure represent what Shallice and Cooper (2011) refer to as compound boxes, within which further sub-processes may exist. The monitoring process, for example, is likely to be a complex process in its own right, and one which requires a goal buffer or similar construct to represent the ongoing goal of trying not to think of the unwanted tune. It is also clear that the process of checking the goal has been achieved must use many of the same rehearsal processes as the voluntary rehearsal of a tune, although this also is an element of the monitoring process which is not explicitly represented within this higher level of description.

FIGURE THREE ABOUT HERE

In summary, in response to the data reviewed on the subject of earworms, he account outlined above is intended to provide a similar "business-as-usual" theory of earworm experiences which is intended to be as theoretically parsimonious as possible because it makes use only of constructs and findings already discussed in the literature and is intended to be applicable to the everyday experience of an involuntary musical recollection. Numerous gaps remain to be filled - "earworms" as reported here are assumed to be involuntary musical images of a kind widely experienced but their relation to similarly involuntary musical experiences of a less everyday and more pathological nature, such as musical hallucinations or musical tinnitus, is unclear. These much more problematic types of musical imagery, which are likely to have very different neurocognitive origins, may react differently to various 
interventions and experimental manipulations. The "perpetual music track" for example, is by definition largely unaffected by the passage of time or by even extreme environmental changes (Brown, 2006) whereas earworms induced in the lab are much more malleable (e.g., Beaman et al., 2015; Hyman et al., 2012). 
Acknowledgements: Thanks to Zulekha Mahfooz for help collecting the data reported here.

Declaration of Interest Statement: This work was not supported by any funding agency or grant programme. No financial interests or benefits have arisen from conducting this research. 


\section{References}

Aben, B., Stapert, S., \& Blokland, A. (2012). About the distinction between working memory and shortterm memory. Frontiers in Psychology, 3, 301.

Anderson, J. R. (2007). How can the human mind occur in the physical universe? Oxford: Oxford University Press.

Baddeley, A. D. \& Andrade, J. (2000). Working memory and the vividness of imagery. Journal of Experimental Psychology: General, 129, 126-145.

Baddeley, A. D., \& Hitch, G. J. (1993). The recency effect: Implicit learning with explicit retrieval? Memory \& Cognition, 21, 146-155.

Bailes, F. (2007). The prevalence and nature of imagined music in the everyday lives of music students. Psychology of Music, 35, 555-570.

Beaman, C. P. (2010). Working memory and working attention: What could possibly evolve? Current Anthropology, 51, S27-S38.

Beaman, C. P., Powell, K., \& Rapley, E. (2015). Want to block earworms from conscious awareness? B(u)y gum! Quarterly Journal of Experimental Psychology, 68, 1049-1057.

Beaman, C. P., \& Williams, T. I. (2010). Earworms ("stuck song syndrome"): Towards a natural history of intrusive thoughts. British Journal of Psychology, 101, 637-653.

Beaman, C. P., \& Williams, T. I. (2013). Individual differences in mental control predict involuntary musical imagery. Musicae Scientiae, 17, 398-409.

Bennett, S. (2002). Musical Imagery Repetition (MIR). Unpublished M. Phil. thesis, Cambridge University, Cambridge , United Kingdom

Berg, I. A. (1953). Observations concerning obsessive tunes in normal persons under stress. Journal of Clinical Psychology, 9, 300-302. 
Bishop, L., Bailes, F., \& Dean, R. (2013). Musical expertise and the ability to imagine loudness. PLOS ONE, 8, e56052.

Brown, S. (2006). The perpetual music track: The phenomenon of constant musical imagery. Journal of Consciousness Studies, 13, 43-62.

Byron, T. P., \& Fowles, L. C. (2015). Repetition and recency increases involuntary musical imagery of previously unfamiliar songs. Psychology of Music, 43, 375-389.

Conrad, R., \& Hull, A. J. (1968). Input modality and the serial position curve in short-term memory. Psychonomic Science, 10, 135-136.

Cotter, K. N., Christensen, A. P., \& Silvia, P. J. (2016). Musical minds: Personality, schizotypy, and involuntary musical imagery. Psychomusicology: Music, Mind \& Brain, 26, 220-225

De La Motte, D. (1993). Melodie. Ein Lese- und Arbeitsbuch [Melody. A reading and workbook]. München. Dtv.

Droit-Volet, S., Ramos, D., Bueno, J. L., \& Bigand, E. (2013). Music, emotion, and time perception: The influence of subjective emotional valence and arousal? Frontiers in Psychology, 4: 417. doi: $10.3389 /$ fpsyg.2013.00417

Eckert, C. (1979). Der "ohrwurm". zur psychopathologie des alltagslebens. [The "ear worm". Psychopathology of daily life]. Psyche, 33, 545-550.

Farrugia, N., Jakubowski, K., Cusack, R. \& Stewart, L. (2015). Tunes stuck in your brain: The frequency and affective evaluation of involuntary musical imagery correlate with cortical structure. Consciousness \& Cognition, $35,66-77$

Floridou, G. A., \& Müllensiefen, D. (2015) Environmental and mental conditions predicting the experience of involuntary musical imagery: An experience sampling method study. Consciousness \& Cognition, 33, 472-486. 
Floridou, G. A., Williamson, V. J., Stewart, L., \& Müllensiefen, D. (2015). The involuntary musical imagery scale (IMIS). Psychomusicology: Music, Mind \& Brain, 25, 28-36.

Halpern, A. R. (1988). Mental scanning in auditory imagery for songs. Journal of Experimental Psychology: Learning, Memory \& Cognition, 14, 434-443.

Halpern, A. R. (2015). Differences in auditory imagery self-report predict neural and behavioural outcomes. Psychomusicology: Music, Mind \& Brain, 25, 37-47.

Halpern, A. R., \& Bartlett, J. C. (2011). The persistence of musical memories: A descriptive study of earworms. Music Perception, 28, 425-432.

Hanczakowski, M., Beaman, C. P., \& Jones, D. M. (2018). Learning through clamor: The allocation and perception of study time in noise. Journal of Experimental Psychology: General. In press.

Hemming, J. (2009). Zur Phänomenologie des Ohrwurms. [On the phenomenology of earworms] Musikpsychologie, 20, 184-207.

Henson, R. N. A. (2001). Neural working memory. In J. Andrade (Ed.) Working memory in perspective. Hillsdale, N.J.: Erlbaum. pp. 151-174.

Hubbard, T. L. (2010). Auditory imagery: Empirical findings. Psychological Bulletin, 136, 302-329.

Husain, F., Levin, J., Scott, J., \& Fjeldstad C. (2014). Recurrent refrains in a patient with multiple sclerosis: Earworms or musical hallucinations? Multiple sclerosis \& related disorders, 3, 276-278.

Hyman I. E., Jr, Burland, N. K., Duskin, H. M., Cook, M. C., Roy, C. M., McGrath, J. C., \& Roundhill, R. F. (2013). Going ga-ga: Investigating, creating and manipulating the song stuck in my head. Applied Cognitive Psychology, 27, 204-215.

Hyman, I. E., Jr., Cutshaw, K. I., Hall, C. M., Snyders, M. E., Masters, S. A., Au, V., \& Graham, J. M. (2015). Involuntary to intrusive: Using Involuntary Musical Imagery to explore individual differences and the nature of intrusive thoughts. Psychomusicology: Music, Mind \& Brain, 25, 14-27. 
Kvavilashvili, L., \& Mandler, G. (2004). Out of one's mind: A study of involuntary semantic memories. Cognitive Psychology, 48, 47-94.

Kvavilashvili, L., \& Schlagman, S. (2011). Involuntary autobiographical memories in dysphoric mood: A laboratory study. Memory, 19, 331-345.

Jakubowski, K., Farrugia, N., Halpern, A.R., Sankarpandi, S.K., \& Stewart, L. (2015). The speed of our mental soundtracks: Tracking the tempo of involuntary musical imagery in everyday life. Memory \& Cognition 43, 1229-1242.

Jakubowski, K., Finkel, S., Stewart, L. \& Müllensiefen, D. (2016). Dissecting an earworm: Melodic features and song popularity predict involuntary musical imagery. Psychology of Aesthetics, Creativity, \& the Arts, 11, 122-135.

Kellaris, J. J. (2001). Identifying properties of tunes that get 'stuck in your head': Toward a theory of cognitive itch. In S. E. Heckler \& S. Shapiro (Eds.), Proceedings of the Society for Consumer Psychology Winter 2001 Conference (pp. 66-67). Scottsdale, AZ: American Psychological Society.

Kosslyn, S. M. (1994). Image and brain: The resolution of the imagery debate. Cambridge, MA: MIT Press. Kozlov, M. D., Hughes, R. W., \& Jones, D. M. (2012). Gummed-up memory: Chewing gum impairs shortterm recall. Quarterly Journal of Experimental Psychology, 65, 501-513.

Kraemer, D. J. M., Macrae, C. N., Green, A. E., \& Kelley, W. M. (2005). Sound of silence activates auditory cortex. Nature, 434, 158.

Kvavilashvili, L., \& Mandler, G. (2004). Out of one's mind: A study of involuntary semantic memories. Cognitive Psychology, 48, 47-94.

Levitin, D. (2006). This is your brain on music: Understanding a human obsession. London: Atlantic. Liikkanen, L. A. (2008). Music in everymind: Commonality of involuntary musical imagery. In K. Miyazaki, Y. Hiraga, M. Adachi, Y. Nakajima, \& M. Tsuzaki (Eds.), Proceedings of the 10th International Conference on Music Perception and Cognition (ICMPC10) (pp. 408-412). Sapporo, Japan. 
Liikkanen, L. I. (2012). Musical activities predispose to involuntary musical imagery. Psychology of Music, 40, 236-256.

Liikkanen, L.A., Jakubowski, K. \& Toivanen, J. (2015). Catching earworms on Twitter: Using big data to study involuntary imagery. Music Perception, 33, 199-216

Lima, C. F., Krishnan, S., \& Scott, S. K. (2016). Roles of supplementary motor areas in auditory processing and auditory imagery. Trends in Neurosciences, 39, 547-542.

Lima, C. F., Lavan, N., Evans, S., Agnew, Z., Haplern, A. R., Shanmugalingam, P., Meekings, S., Boebinger, D., Ostarek, M., McGettigan, C., Warren, J. E., \& Scott, S. K. (2015). Feel the noise: Relating individual differences in auditory imagery to the structure and function of sensorimotor systems. Cerebral Cortex, $11,4638-4650$.

McCullough Campbell, S., \& Margulis, E. H. (2015). Catching an earworm through movement. Journal of New Music Research, 44

Müllensiefen, D., Fry, J., Jones, R., Jilka, S., Stewart, L. \& Williamson, V. J. (2014). Individual Differences Predict Patterns in Spontaneous Involuntary Musical Imagery. Music Perception, 31, 323-338.

Müllensiefen, D., Gingras, B., Musil, J., \& Stewart L. (2014). The musicality of non-musicians: An Index for assessing musical sophistication in the general population. PLOS ONE, 9(2): e89642.

Murphy, S., Spence, C., \& Dalton, P. (2017). Auditory perceptual load: A review. Hearing Research, 352, 40-48.

Nairne, J. S. (1990). A feature model of immediate memory. Memory \& Cognition, 18, 251-259.

Newell, A. (1990). Unified theories of cognition. Cambridge, Ma.: Harvard University Press.

Penton-Voak, I. S., Edwards, H., Percival, A., \& Wearden, J. (1996). Speeding up an internal clock in humans? Effects of click trains on subjective durations. Journal of Experimental Psychology: Animal Behavior Processes, 22, 307-320. 
Poe, E. A. (1845/1938). The imp of the perverse. Reprinted in The complete tales and poems of Edgar Allan Poe. New York: Random House.

Pylyshyn, Z. W. (2003). Return of the mental image: Are there really pictures in the brain? Trends in Cognitive Sciences, 7, 113-118.

Raine, A. (1991). The SPQ: A scale for the assessment of schizotypal personality based on DSM-III-R criteria. Schizophrenia Bulletin, 17, 556-564.

Reason, J. (1993). Self-report questionnaires in cognitive psychology: Have they delivered the goods? In: A. D. Baddeley \& L. Weiskrantz (Ed.s) Attention: Selection, awareness, and control. A tribute to Donald Broadbent. Oxford: OUP.

Reisberg, D., Smith, J. D., Baxter, D. A., \& Sonenshine, M. (1989). “Enacted” auditory images are ambiguous: "Pure" auditory images are not. Quarterly Journal of Experimental Psychology, 41A, 619641.

Sacks, O. (2007). Musicophilia: Tales of music and the brain. New York: Random House.

Smith, J. D., Wilson, M., \& Reisberg, D. (1995). The role of subvocalization in auditory imagery. Neuropsychologia, 33, 1433-1454.

Shallice, T., \& Cooper, R. P. (2011). The organisation of mind. Oxford: Clarendon Press.

Storm B. C., Bjork E. L., \& Bjork R. A. (2008). Accelerated relearning after retrieval-induced forgetting: The benefit of being forgotten. Journal of Experimental Psychology: Learning, Memory \& Cognition, 34, $230-236$.

Surprenant, A. M., \& Neath, I. (2009). Principles of memory. Hillsdale, N.J.: Psychology Press.

Talarico, J. M., \& Rubin, D. C. (2003). Confidence, not consistency, characterizes flashbulb memories. Psychological Science, 14, 455-461.

Taylor, S., McKay, D., Miguel, E. C., de Mathis, M. A., Andrade, C. et al. (2014). Musical obsessions: A comprehensive review of neglected clinical phenomena. Journal of Anxiety Disorders, 28, 580-589. 
Twain, M. (1876/1878). A literary nightmare. Reprinted in Punch, brothers, punch! and other stories. New York: Slote, Woodman \& Co.

Von Restorff, H. (1933). Analyse von Vorgängen im Spurenfeld. I. Über die Wirkung von Bereichsbildungen im Spurenfeld. [Analysis of processes in the trace field. I. On the effect of field formations in the trace field.] Psychologische Forschung, 18, 299-342.

Ward, J, Huckstep, B, Tsakanikos, E, (2006). Sound - colour synaesthesia: To what extent does it use cross-modal mechanisms common to us all? Cortex, 42, 264-280

Wegner, D. M. (1989). White bears and other unwanted thoughts. Suppression, obsession, and the psychology of mental control. New York: Guilford.

Wegner, D. M. (1994). Ironic processes of mental control. Psychological Review, 101, 34-52.

Wegner, D. M. (2002). The illusion of conscious will. Cambridge, Ma.: MIT Press.

Wegner, D. M., Schneider, D. J., Carter, S., III, \& White, T. (1987). Paradoxical effects of thought suppression. Journal of Personality \& Social Psychology, 53, 5-13.

Wegner, D. M. \& Zanakos, S. (1994). Chronic thought suppression. Journal of Personality, 62, 615-640.

Weisberg, R. W. (2015). Toward an integrated theory of insight in problem solving. Thinking \& Reasoning, 21, 5-39.

Williams, T. I. (2015). The classification of involuntary musical imagery: The case for earworms. Psychomusicology: Music, Mind \& Brain, 25, 5-13

Williamson, V. J. \& Jilka, S. R. (2014). Experiencing earworms: An interview study of Involuntary Musical Imagery, Psychology of Music, 42, 653-670.

Williamson, V. J., Hilka, S. R., Fry, J., Finkel, S., Müllensiefen, D., \& Stewart, L. (2012). How do "earworms" start? Classifying the everyday circumstances of Involuntary Musical Imagery, Psychology of Music, 40, 259-280. 
The History of the Earworm

Williamson, V. J., Liikkanen, L. A., Jakubowski, K., \& Stewart, L. (2014). Sticky tunes: How do people react to earworms. PLOS ONE 9: e86170 
Appendix: Methodological and analytic detail for reported results.

Design and Participants. One hundred and six undergraduate students participated in return for course credit. Eight-eight participants completed a $2 \times 2$ between participants design with 22 participants in each condition as outlined below. Analyses of variance are based upon these 88 participants. A further eighteen participants were recruited subsequent to this study and took part only in the song with lyricsno gum condition. Correlation coefficients were calculated for these participants plus the 22 participants who experienced the same condition in the larger design (giving a total $n=40$ for the correlations). No statistical analyses were attempted beyond those reported.

Procedure. All participants were tested individually. They each completed a paper copy of the Bucknell Auditory Imagery Scale. The chorus of the tune Shape of You by Ed Sheeran was then played over headphones for 30 seconds. There were two versions of this tune - a lyrical and an instrumental version. No participant was exposed to both conditions. Half of the participants were provided with a Wrigley's stick gum which was on the table at the start of the experiment. Once the tune had been played the experimenter asked the participants in this condition to chew the gum "potently" or "vigorously" for the remainder of the experiment. All participants were given instructions not to think of the tune they had just heard for the next three minutes immediately after they were exposed to the tune. They were told that if at any time during the three minutes they thought of the tune they must press the " $\mathrm{T}$ " key on a computer keyboard and if they "heard" the tune in their head then they should press " $\mathrm{Z}$ " on the computer keyboard.

Results. Correlation coefficients are reported in Table 1. Analyses of variance show a main effect of chewing gum on the number of involuntary thoughts about the target tune (Figure 2 upper panel), $F(1$, $84)=12.23, p=.001$ but no main effect of type of tune (lyrical vs. instrumental), $F(1,84)=2.43, p=.123$ and no interaction, $F(1,84)=.64, p=.426$. There was a main effect of chewing gum on the number of 
involuntary tunes "heard", $F(1,84)=20.14, p<.001$ and also an effect of the type of tune, $F(1,84)=8.28$, $p=.005$. The interaction was again nonsignificant, $F(1,84)=31.92, p=.105$. 


\begin{tabular}{|l|l|l|l|}
\hline & Heard & BAIS-Vividness & BAIS-Control \\
\hline Thought & .157 & .021 & .145 \\
\hline Heard & & $.444^{* *}$ & $.490^{* *}$ \\
\hline BAIS-Vividness & & & $.448^{* *}$ \\
\hline
\end{tabular}

Table 1. Pearson's correlation coefficients between the number of tune-related thoughts, the number of earworms "heard" and scores on the Bucknell Auditory Imagery Scale. * Significant at $p<.05, * *$ Significant at $p<.01$, 2-tailed. $(n=40)$. 

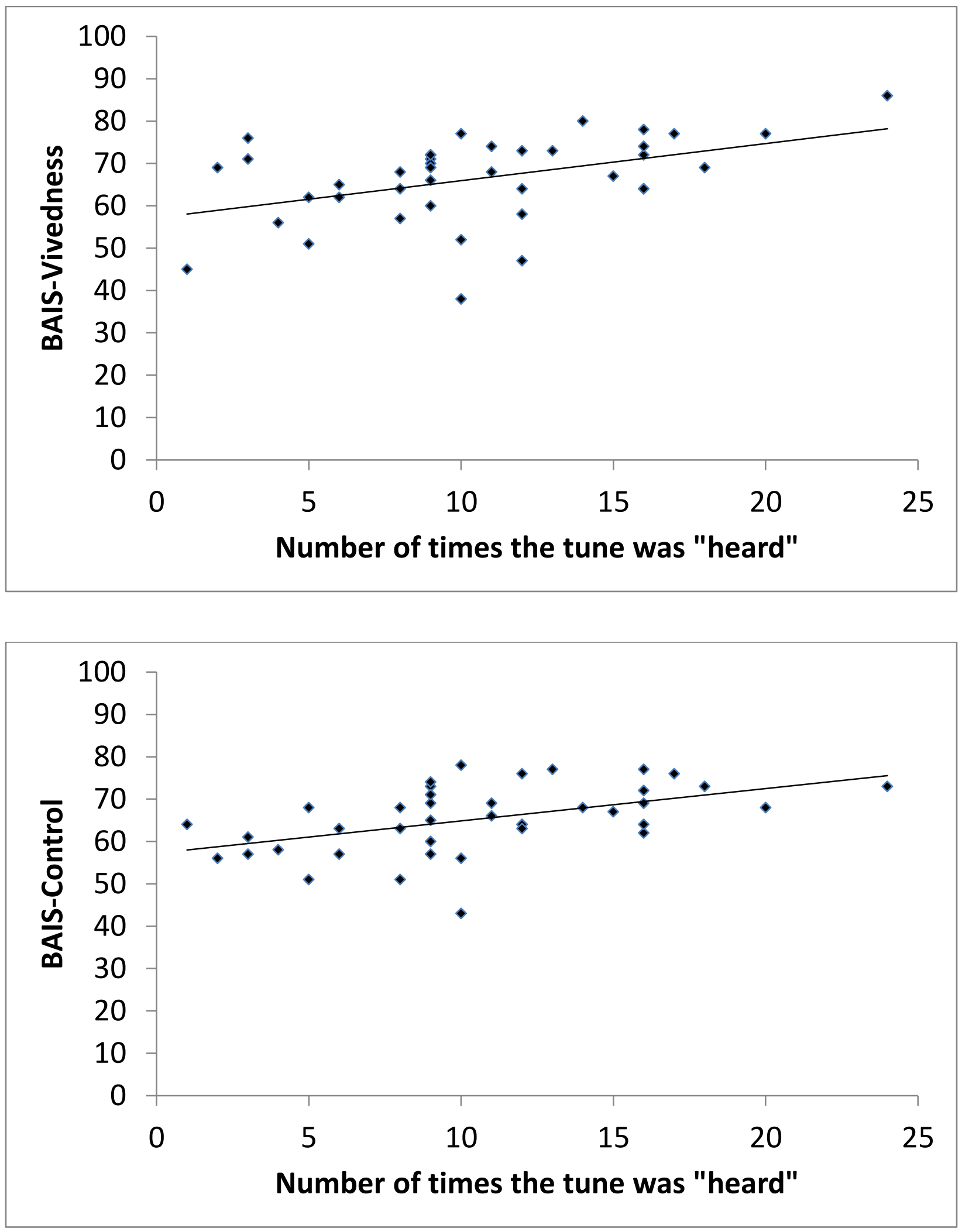

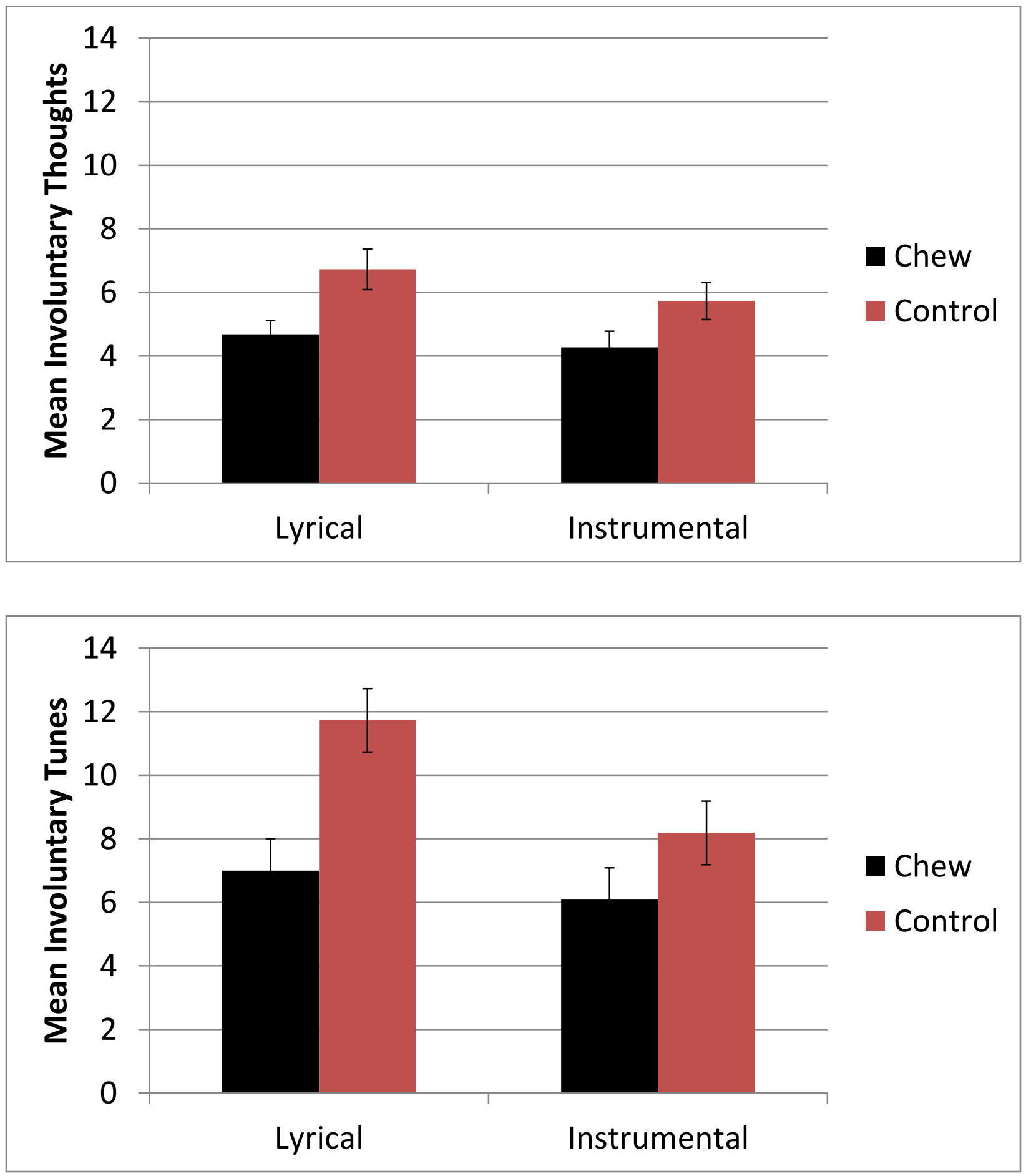


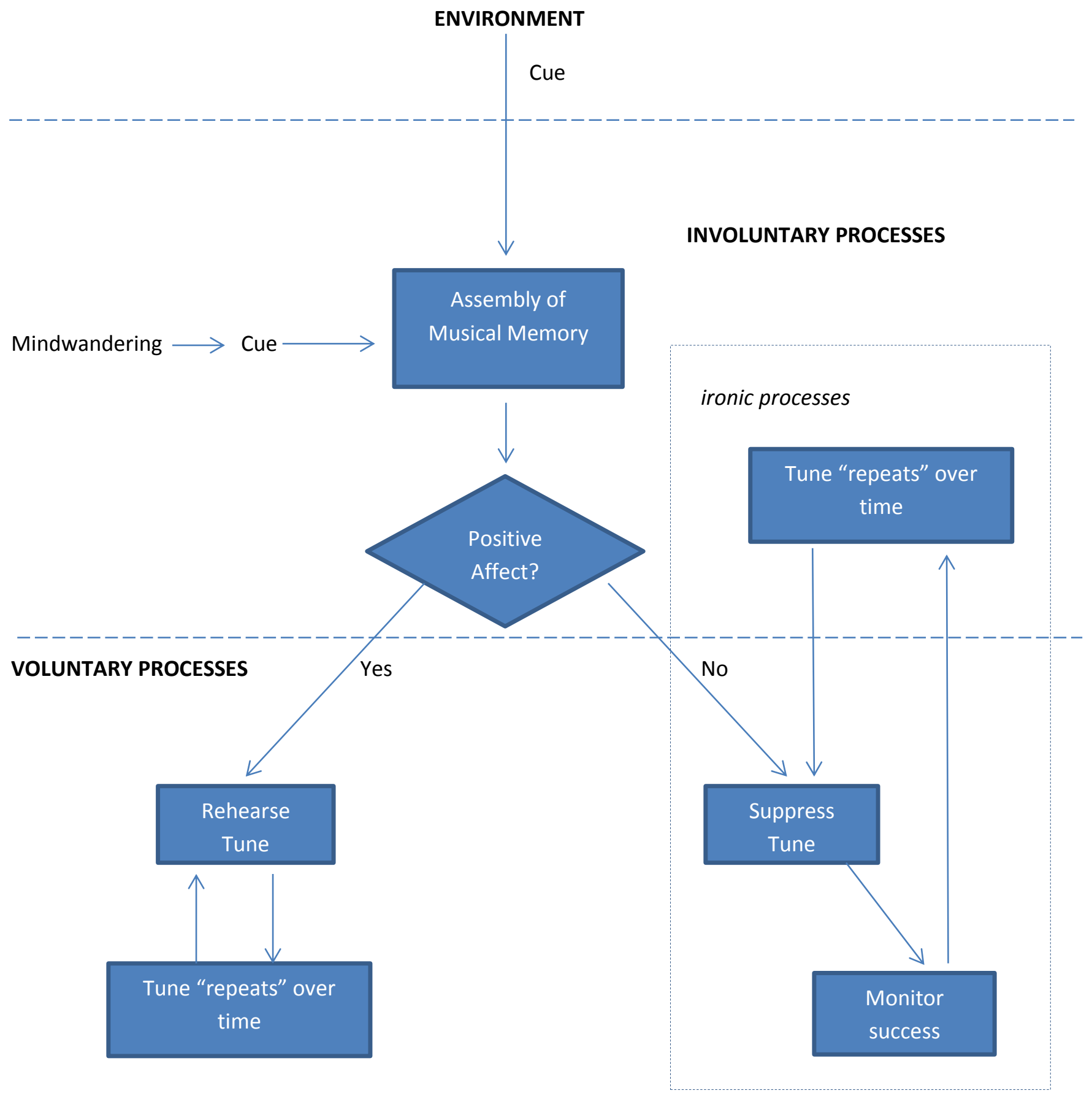


Figure Captions

Figure One: Scatterplots for the statistically significant correlations reported in Table 1 between the number of times a tune was "heard" and the Bucknell Auditory Imagery scales for Control (BAIS-C) and Vividness (BAIS-V) of auditory imagery.

Figure Two: The mean number of involuntary thoughts about the tune (upper panel) and the mean number of times the tune was involuntarily "heard" (lower panel) as a function of whether the tune contained lyrics or was instrumental, and whether participants were asked to chew gum. Error bars are standard error, inferential statistics based upon these data are given in the appendix.

Figure Three: Graphical depiction of means by which a musical image might be involuntarily cued and subsequently maintained, either voluntarily or involuntarily via ironic processes. The figure distinguishes between voluntary and involuntary processes with ironic mental control resulting from the necessary contribution of voluntary suppression processes. This figure is intended purely as indicative and is not complete. For example, success monitoring can itself be broken down into a number of sub-components not explicitly given here (Shallice \& Cooper, 2011). 